\title{
Gongorismo y conceptismo, en la poesía lírica de Sor Juana
}

Tos críticos literarios parece que están de acuerdo al considerar $\mathcal{L}$ a Sor Juana Inés de la Cruz (1651-1695) como uno de los genios poéticos más grandes que América ha producido. Menéndez y Pelayo la juzga superior a todos los poetas del reinado de Carlos II. El señor Torres-Rioseco la considera como "el último gran poeta lírico de España y el primer gran poeta de América". ${ }^{1}$ Pero la unanimidad de opinión desaparece tan pronto como se empieza a estudiar en detalle la obra de Sor Juana. El gongorismo y el conceptismo de su obra son puntos sobre los cuales se han expresado opiniones muy diversas. Don José María Vigil afirma que la obra de Sor Juana está libre de todo gongorismo. Esto es lo que dice:

Un crítico español, el señor Mesonero Romanos, ha dicho, por ejemplo, que es peculiar o frecuente en Sor Juana el estilo culto, metafórico y alambicado... Pues bien, nada más destituído de fundamento que semejante aserción, siendo verdad precisamente lo contrario, que en sus composiciones son muy pocas las faltas de gusto que la decadencia había introducido en el estilo literario, pudiéndose notar en lo general esa claridad de pensamiento, esa precisión de imágenes, ese lenguaje correcto y apropiado a la pasión que expresa y que caracteriza a los buenos escritores del siglo XVIII. 2

Añade además, para probar su punto:

Como si la misma Sor Juana hubiese querido de antemano sincerarse de esta clase de inculpaciones, dejó entre sus obras el Sueño, extensa imitación de Góngora, a la cual puede aplicarse en todas sus partes el juicio del crítico español que he citado, 3 
Así pues, don José María Vigil admite que Sor Juana es gongorina, pero sólo en una de sus composiciones. El señor Toussaint incluye, además del famoso Sueño, varios de sus sonetos, pero defendiéndola también de la acusación de ser gongorina:

... eso no basta a hacer de Sor Juana un poeta gongorino; junto a su Sueño y sus sonetos, están sus admirables villancicos, con su aliento de poesía del siglo XVI...., están sus romances, como el admirable de la "vana ciencia", en que imita el grave y sereno filosofar de Lope de Vega....4

Otros, al contrario, la acusan de ser siempre gongorina. Así dice Pimentel:

El carácter general de las poesias de Sor Juana, lo mismo que el de todas sus obras, es el gongorismo o culteranismo ... Llevada por el torrente, admiró a Góngora y trató de imitarle, principalmente en una extensa poesía que intituló $E l$ sueño, composición que era la predilecta de nuestra poetisa, pues en su catta a Filotea confiesa que fué la única que escribió con su gusto ...5

$\mathrm{Y}$ añade al hablar de otras composiciones: "en algunas poesías de Sor Juana, donde el gongorismo se modera más o menos ...," ${ }^{6}$ dando a entender que, en su opinión, éste no está nunca verdaderamente ausente de ninguna de las composiciones de la poetisa.

La señorita Schons indica que Sor Juana es la única en México que imita más que a medias la sintaxis de Góngora, haciendo notar al mismo tiempo que:

A good example of how so-called gongorism in Mexico differs from that developed by Góngora himself is the Primer Sueño by Sor Juana Inés de la Cruz. 7

El señor Abreu Gómez señala las diferencias entre el estilo. del cordobés y el de la monja mexicana, considerando la influencia de Góngora en Sor Juana como una influencia negativa:

De Góngora no recoge sino las formas externas, las periféricas. Tal se advierte en Primer sueño, donde sigue sólo la envoltura de Las Soledades. Efunde a su poema, en cambio, una estructura interna, un valor filosófico contrario no sólo al espíritu del estilo barroco, sino adverso a la poética del cordobés. 8 
Una de las principales razones por las cuales se han expresado opiniones tan diversas sobre el gongorismo de Sor Juana es que su obra, tan heterogénea, ha sido juzgada a veces por una mínima porción de ella. Parece esencial, por lo tanto, no para añadir una opinión más, sino para poder hacer un estudio definitivo del gongorismo y del conceptismo en la poesía lírica de Sor Juana - la parte más importante de su obra desde el punto de vista literario-, comenzar por una breve consideración de lo que ésta comprende.

Dejando a un lado sus obras en prosa, sus loas, comedias y autos sacramentales, existen, según los estudios bibliográficos más recientes, 242 composiciones líricas de Sor Juana Inés de la Cruz. Comprenden éstas sonetos, romances, glosas, redondillas, quintillas, décimas, endechas, liras, villancicos, anagramas, alguna silva, sus "ovillejos" y un laberinto endecasílabo.

Este estudio tratará dé analizar los varios elementos gongorinos y conceptistas que se encuentran en estas poesías, a fin de poder determinar hasta qué punto Sor Juana es conceptista y gongorina.

Sor Juana escribió la mayoría de sus obras entre 1670 y 1690 , unos cincuenta años después de Góngora. No puede haber la menor duda de que conocía bien sus obras, pues eran muy leídas, aplaudidas e imitadas en la Nueva España de sus días, como se puede ver por los centones de sus obras, compuestos para los certámenes poéticos. Si Sor Juana no escribió ninguna composición de esta especie:, sí tiene varias imitaciones directas de las obras del gran cordobés. En el Polifemo usa Góngora la expresión:

$$
\text { ... de espuma canos } 9
$$

que Sor Juana parece imitar en:

cisnes de cana espuma. 10

En la misma composición dice Góngora:

Que si la mia puede offrecer tanto

Clarin, i de la Fama no segundo,

$\mathrm{Tu}$ nombre oiran los terminos del mundo, 11

y Sor Juana:

$Y$ ya en trompas oyeron, ya en clarines

los opuestos confines

del orbe, de tu fama los acentos. 12 
En los sonetos de Sor Juana hay también indicios de imitación. Así el verso de Góngora:

en tierra, en humo, en polvo, en sombra, en nada. 13

puede haber influido en Sor Juana cuando escribió:

Es cadáver, es polvo, es sombra, es nada. 14

Dos sonetos escritos por estos dos poetas también pueden tener alguna relación. Dirigiéndose a una rosa dice Góngora:

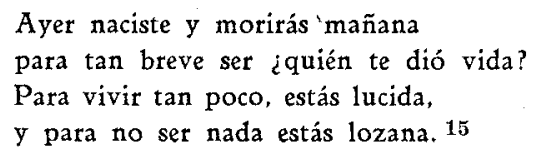

Es sin duda, la misma idea que tiene Sor Juana; pero, ¿quién puede decir que se la inspiró Góngora y no Lope de Vega, Rioja, o la naturaleza misma? Dice este soneto:

Miró Celia una rosa que en el prado ostentaba feliz la pompa vana $y$ con afeites de carmin y grana bañaba alegre el rostro delicado;

y dijo: goza, sin temor del hado, el curso breve de tu edad lozana, pues no podrá la muerte de mañana quitarte lo que hubieres hoy gozado:

y aunque llegue la muerte presurosa y tu fragante vida se te aleja, no sientas el morir tan bella y moza;

mira que la experiencia te aconseja que es fortuna morirte siendo hermosa y no ver el ultraje de ser vieja. 16

El ejemplo más notable de imitación de Góngora es el famoso Primero sueño. Muchos críticos han dicho que ella misma confesó haberlo escrito imitando al gran vate cordobés; los primeros editores de sus obras reconocieron esto, pues el título dice: "Primero Sueño, que así tituló y compuso la madre Juana Inés de la Cruz, imitando a Góngora". Es una imitación de las Soledades: usa la misma 
forma métrica - la silva-y su extensión, 975 versos, se acerca a la de la Primera soledad, 1091 o 1098 según la edición. La sintaxis de este poema es, según la señorita Schons, la imitación más perfecta de la de Góngora que se ha encontrado en México. Tanto el ambiente como el asunto de que trata esta poesía de Sor Juana, difieren completamente de los del poema de Góngora:

The atmosphere of the poem is altogether different. In the latter is one of light and color, in the former all is dark, vague, and impressionistic. In the "Soledad" al is clear-cut imagery. The second notable difference is to be found in the subject matter, which in the "Sueño" is didactic and philosophical, whereas the "Soledad" is merely a description of nature. Sor Juana goes into the physical processes on sleep and the psychological properties of dream ... The poem is characterized by extreme subtlety and obscurity, due not to the language but to the abstract nature of the thought. The poem has none of the beauties of the "Soledades" and is far more difficult to understand. 17

Para el señor Abreu Gómez, la gran diferencia entre estos dos poemas es una diferencia de tiempo. El gongorismo que conoció Sor Juana, ya no era el mismo que el del tiempo de Góngora:

El gongorismo por su distancia en el tiempo, no llega a Sor Juana por los cartiles del medio ambiente, sino que se traba en su poesia, conscientemente, por mera licencia que recibe de la monja. Además ¿no significan nada las variaciones filosóficas que se realizan de una a otra época? Todavía en el tiempo de Góngora está vivo, pleno, uno de los elementos que constituyen el ideal del Renacimiento: la afirmación de la naturaleza. La estética del culteranismo puede, más o menos, disfrazar esta afirmación por medio del frecuente uso dé metáforas y perifrasis pero el desarraigo de la realidad no se realiza totalmente. En el tiempo de Sor Juana estas relaciones no son ya tan estrictas. Los dos mundos (el hombre y la naturaleza) se separan. Hasta hay un atisbo de esta verdad en "E1 Sueño". Y es que la literatura participa del espiritu analítico -racionalista- de la época. 18

Para hacer más inteligible lo relativo a este largo poema, hay que dar una idea más detallada del asunto de que trata. El señor Vossler lo resume como sigue:

...es un asombro ante el misterio cósmico de los fenómenos, hombre y mundo. Un asombro que no es infantil, sino más bien 
consciente, y contempla las cosas de todos los días, demasiado conocidas, a través de nuevas fuerzas decididas a la exploración, y sin embargo, insuficientes. Es el grado precedente a la educación y a la ciencia, una lucha con el enigma de la naturaleza y un sucumbir ante lo desmesurado del problema y del tema. Con recursos audaces y seudo-exactos de pensamiento y lenguaje, se tratan los sucesos fisiológicos del sueño, de las actividades del co. razón y los pulmones, de la digestión y de la alimentación del cerebro, y se describen métodos curativos, experimentos de proyección, fenómenos astronómicos y meteorológicos, y otros asuntos de un modo mitad científico, mitad fantástico. Concepto y percepción, exploración y mito colaboran juntos, alternan y se estimulan en esfuerzos crecientes, excitados y funambulescos, no pudiendo calmarse ni en la crítica, ni en la humilde autorresignación, ni en la entrega mística, sino sólo en el agotamiento, es decir, en la claridad de la mañana. ${ }^{19}$

Antes de examinar los diferentes elementos gongorinos de que está lleno este poema, sería bueno considerar algunos versos, para ver cómo estos retruécanos, metáforas, etc., no son elementos separados, sino que forman un conjunto, tan verdaderamente gongorino como el Polifemo o las Soledades:

Piramidal funesta, de la tierra nacida sombra, al cielo encaminaba de vanos obeliscos punta altiva, escalar pretendiendo las estrellas; si bien sus luces bellas

-esemptas siempre, siempre rutilantes-

la tenebrosa guerra que con negros vapores le intimaba la pavorosa sombra fugitiva burlaban tan distantes, que su atezado ceño al superior convexo aun no llegaba del orbe de la diosa que tres veces hermosa con tres hermosos rostros ser ostenta; quedando sólo dueño del aire que empañaba con el aliento denso que exhalaba. ${ }^{20}$

Esta frase de diez y ocho versos, en sí es gongorina y recuerda los sonetos de Góngora escritos en una sola frase. El tono es culto y afectado, las inversiones frecuentes. Así en: 
nacida sombra...

... de vanos obeliscos punta altiva,

escalar pretendiendo las estrellas...

Estas características pueden aplicarse, no sólo a los versos que se acaban de citar, sino a todo el poema.

Las obscuras alusiones mitológicas contenidas en el Primero sueño también son características del gongorismo. Por ejemplo, cuando dice:

$\mathrm{Y}$ aquellas que su casa campo vieron volver, sus telas yerba - a la deidad de Baco inobedientes ya no historias contadas diferentesen forma si afrentosa transformadas... $Y$ entre ellos la engañosa encantadora Almone, a los que antes en peces transformó simples amantes, transformada también vengaba ahora... Y el rey -que vigilancias afectabaaun con abiertos ojos no velaba. El de sus mismos perros acosado, monarca en otro tiempo esclarecido, timido ya venado, con vigilante oído, del sosegado ambiente, al menor perceptible movimiento que los átomos muda, la oreja alterna aguda $y$ el leve rumor siente que aun le altera dormido, 21

Las figuras que usa para decir las cosas más ordinarias son también característicamente cultas. Así, el aceite es el licor

... que el árbol de Minerva

de su fruto de prensas agravado,

congojoso sudó y rindió forzado, 22

Tampoco le faltan metáforas apropiadas, aunque menos complejas que las que usa Góngora:

El mar, no ya alterado, ni aun la instable mecía cerúlea cuna donde el sol dormía ...23 
... y aquella del calor más competente centrifica oficina

próvida de los miembros despensera . . 24

Esta, pues, si no fragua de Vulcano,

templada hoguera del calor humano...25

El elemento que ayuda más a conservar la impresión de gongorismo es la sintaxis de todo el poema. Sería imposible dar aquí todos los ejemplos de transposición e imitación de la sintaxis latina que hay en él, pero bastarán unos ejemplos:

desde la que pajiza vive choza...

a la que junco humilde, humilde mora . . . 26

y él venga su expulsión haciendo activo. 27

que intelectuales claras son estrellas. . . 28

inanimada estrella,

bien que soberbios brille resplandores. 29

Las reminiscencias directas de las obras de Góngora tampoco faltan en el Primero sueño de Sor Juana. El señor Abreu Gómez las ha señalado como sigue:

"Escalar pretendiendo",

Góngora, "Soledad Primera".

"Escalar pretendiendo las estrellas"

Sor Juana, "Primero sueño", v. 4.

"el cóncavo ajustado de los cielos"

Góngora, "Soledad Primera".

"al superior convexo..."

Sor Juana, "Primero sueño", v. 12.

". . infame turba de nocturnas aves"

Góngora, "E1 Polifemo".

"La leve turba, descansando al viento"

Sor Juana, "Primero sueño", v. 128.

"... peinat al viento",

Góngora, "El Polifemo".

". . las dos plumadas velas, ya peinando

con las garras el aire..."

Sor Juana, "Primero sueño", v. 347.30

Es imposible negar que este poema sea gongorino; pero, como dice el señor Abreu Gómez, esto marca una imitación, no una in- 
fluencia. Una composición no puede caracterizar a una poetisa que ha escrito tanto. Es necesario hacer un estudio del gongorismo que aparece en sus otras obras, antes de poder dar una opinión definitiva sobre este punto. La división por formas métricas parece ser la mejor, para dar una idea de la proporción de composiciones que son gongorinas y de las que no lo son.

Además del Primero sueño, escribió Sor Juana otras tres silvas. La que comienza "No cabal relación, indicio breve" es más corta que el Primero sueño, y de carácter más bien épico que lírico. Sin haber llamado tanto la atención de los críticos, tiene las mismas características gongorinas que la anterior. Cada período alcanza, por lo general, unos quince versos. Las metáforas se acumulan y se mezclan, como cuando dice:

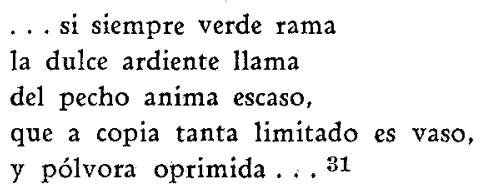

Más gongorina que ninguna de las metáforas del Primero sueño es quizás ésta :

de la carga pesada
de férrea condensada exhalaciones
sudando en densas nubes la agonía
-víbora de vapores espantosa,
cuyo silbo es el trueno
que al cielo descompone la harmonía,
al vaporoso ceño,
que concibió la máquina fogosa,
que ya imitó después la tiranía
en ardiente fatal artillería-...

Tampoco faltan alusiones mitológicas, en esta silva. Las inversiones son menos frecuentes que en el Sueño; pero el uso de las metáforas complicadas y las imitaciones directas de Góngora, que tampoco faltan, dan una impresión de gongorismo, tanto en los elementos aislados como en el conjunto de la poesía. La señorita Schons hace notar que esta silva, como las de Góngora, es de forma irregular. 
La tercera silva también es gongorina. No se puede estudiar mucho aquí, pues no es una poesía lírica sino la descripción del Neptuno alegórico. Una breve cita, sin embargo, hará ver lo gongorina que es:

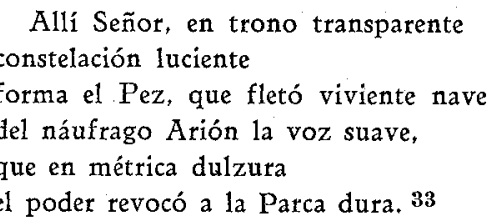

La composición intitulada "Ovillejos" por Sor Juana, es una burla del gongorismo:

Sigue Sor Juana -én actitud de imitación- la obra cómica de Jacinto Polo... Su espíritu clásico - como le pasa al propio Polo- la lleva a burlarse de los modos gongorinos decadentes: vocabulario, mitología, erudición. La opinión anticulterana de Polo no parece meramente reflejada en Sor Juana; antes, con Ia precisión de su estilo lógico y con sus expresiones irónicas, muestra cual es su criterio sobre el particular y cuáles sus preferencias estéticas. Tras estos Ovillejos, entre burlas, mejor que pintar el retrato de la tal Lizarda, traza una sátira intencionada del gongorismo de su época y, más especialmente del de México. Creo también que en esta composición de Sor Juana está presente la lección, igualmente anticultista, de Lope de Vega, desprendida de su Gatomaguia. ${ }^{34}$

Pero si Sor Juana se podía burlar de manera tan deliciosa como lo hace en los Ovillejos, de la manera gongorina de pintar un retrato, no por eso se privó a sí misma del gusto de escribir tales composiciones y exageraciones. Al describir a la Condesa de Galve dice que:

... Ulises es su pelo con Alejandro, porque es sutil el uno y el otro largo.

Un Colón es su frente por dilatada, porque es quien su Imperio más adelanta. 


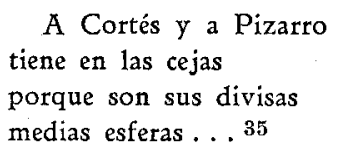

La composición en que describe a la señora de Paredes, es quizás más característica aún del gongorismo:

Lámina sirva el cielo al tetrato,

Lísida, de tu angélica forma.

Cálamos forme el sol de tus luces;

sílabas las estrellas compongan.

Cárceles tu madeja fabrica,

dédalo que sutilmente forma

vínculos de dorados ofires,

tíbares de prisiones gustosas . . . ${ }^{36}$

Otra poesía esdrújula que escribió, es también gongorina, tanto por la sintaxis latina como por las alusiones mitológicas y metáforas extraordinarias. Los versos más característicos del gongorismo son estos:

Alamos no a tu nombre vinculan rústicas de su piel bibliotecas... 37

En general, las treinta y cuatro décimas escritas por Sor Juana no son gongorinas. Contienen alusiones a la antigüedad clásica, cierto discreteo retórico y juegos de palabras; pero éstas son características del conceptismo, más bien que del gongorismo, y en realidad se encuentran también, hasta cierto punto, en poesías de otros períodos y que pertenecen a otras escuelas literarias. Las únicas décimas que son gongorinas son las que forman parte de la descripción del Neptuno alegórico; contienen versos como estos:

De Hércules vence el furioso curso Neptuno prudente... 38

Las diez endechas escritas por Sor Juana no tienen muchas de las características del gongorismo. Las que expresan el sentimiento que padece una mujer amante de su marido muerto parecen un poco cultas a veces; pero quizás sólo sea la fuerza del dolor la que da esta impresión: 


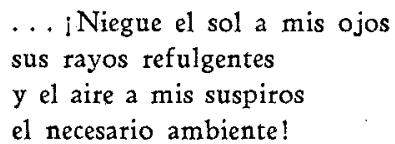

¡Cúbrame eterna noche y el siempre obscuro Lete borre mi nombre infausto del pecho de las gentes! . . 39

En conjunto los cincuenta y cinco romances octosílabos escritos por Sor Juana no dan la impresión de ser gongorinos; sin embargo, aquí y allá se encuentra una u otra de las características del gongorismo. La más común es la de hacer alusiones clásicas, a veces ocultas, a veces acumulando nombres. Basten algunos ejemplos:

... Venus del mar lusitano,

Digna de ser bella madre

De amor, más que la que a Chipre

Debió cuna de cristales.

Gran Minerva de Lisboa.

Mejor que la que triunfante

De Neptuno, impuso a Atenas

Sus insignias literales . . 40

Vos, a quien por Tolomeo

veneraran los egipcios,

por Solón los atenienses,

los romanos por Pompillo...

Qué Saturno, qué Carondas,

qué Filalao, qué Anicio,

qué Samolio, qué Seleuco,

qu Rómulo, qué Tranquilo... 41

Las metáforas atrevidas aparecen sobre todo en sus comparaciones y retratos. Así, al hablar del hijo de los virreyes, lo llama Julio César, Augusto, rosa, pimpollo, carbunclo, etc. :

... Nació de aromas reales entre los sagrados humos, más bello flamante fénix, que el que el Arabia prođujo... 42

E1 retrato de la Condesa de Galve está lleno de estas comparaciones:

E1 Soberano Gaspar par es de la bella Elvira, 
vira de amor más derecha,

hecha de sus armas mismas.

Su ensortijada madeja

deja, si el viento la enriza,

riza tempestad, que encrespa

crespa botrasca a las vidas. . ${ }^{43}$

No hay ningún romance en que Sor Juana use sintaxis latina comc en el Sueño, pero sí hay una que otra inversión como ésta:

... Celebrad ese de vuestra

propia aprehensión simulacro...44

El romance que en su conjunto da una impresión más marcada de gongorismo, sin por eso acercarse siquiera a la que dan las silvas, es el dirigido al Arzobispo de México pidiéndole el sacramento de la confirmación:

$$
\begin{aligned}
& \text {... Yo, señor (ya lo sabéis), } \\
& \text { he pasado un tabardillo, } \\
& \text { que me lo dió Dios, y que } \\
& \text { Dios me lo haya recibido. }
\end{aligned}
$$

Donde con las critiqueces

de sus términos impios.

a ardor extraño cedia,

débil el calor nativo.

Los instrumentos vitales cesaban ya en su ejercicio, ocioso el copo en Lachesis él vió en Cloto baldío.

Atropos sola inminente, con el golpe ejecutivo del frágil humano estambre, cercenaba el débil hilo.

De aquella fatal tijera, sonaban a mis oidos opuestamente hermanados, los inexorables filos ...45

Las glosas, redondillas y liras no son gongorinas: sus fases son cortas, su estilo claro. El lenguaje de los villancicos no es ge- 
neralmente culto; pero la mezcla de lenguas y de elementos religiosos y profanos sí son barrocos.

Muchas veces se ha dicho que los sonetos de Sor Juana, de los cuales se conocen sesenta y nueve, son gongorinos; otras veces, que son conceptistas. Para no dar más que un ejemplo, en su Historia literaria de la América Española dice el señor Coester: a despecho del culteranismo del siguiente soneto es fácil inclinarse a creer que sus palabras revelan algún secreto de su corazón

"Detente, sombra de mi bien esquivo .. .46

a lo cual comenta el señor Abreu Gómez, que éste

...es precisamente uno de los sonetos que pueden presentarse para demostrar el no culteranismo de Sor Juana; tal es su conceptismo, su falta de superficie. Todo en él es profundo, claro. 47

Un estudio más detallado parece imponerse, para determinar este punto. Para evitar errores, sería bueno recordar las definiciones de ambas tendencias:

El culteranismo fué una tendencia literaria relativa a la expresión o a la forma que se caracterizó por lo selecto del lenguaje; por la introducción de muchas palabras nuevas .... por el prurito de reflejar o imitar, en muchas ocasiones, la sintaxis latina; por los artificios del hipérbaton y por las trasposiciones; por las hipérboles metáforas, no pocas veces atrevidas; por las alusiones mitológicas, históricas y geográficas, no de lo más conocido sino de lo más recóndito. 48

Otra tendencia literaria surgió en el siglo XVII, aparte del culteranismo, a veces como contradicción de éste, y en ocasiones dándose uno y otro en un mismo escritor; tal fué el conceptismo, que se distinguió por lo sutil, agudo e ingenioso de los pensamientos, y por la aféctación, el contraste y doble sentido de ellos: son frecuentes en él la antítesis, equívocos, juegos de palabras y retruécanos; en cambio, gustaba mucho menos que los escritores gongorinos de alusiones mitológicas y eruditas. 49

Sonetos gongorinos por su sintaxis, metáforas y trasposiciones no pasan el número de cinco. Hay otros veintiocho en que se encuentran algunas de las características de esta escuela; pero, en once casos, unidas a las del conceptismo. Además de estos once, escribió Sor Juana veintidós más en los que domina el conceptismo, lo que 
hace treinta y tres sonetos en que se encuentra éste. Sólo en catorce sonetos no se encuentran marcadas características de ninguna de estas tendencias. Estos sonetos son más bien del estilo de la escuela sevillana. Muy pocas veces se encuentra en los sonetos el estilo tradicional español que aparece tan a menudo en las glosas y redondillas de Sor Juana.

Los sesenta y nueve sonetos podrían servir de ejemplos; pero como es preciso limitarse, se dará solamente un ejemplo de cada una de estas tendencias.

Un soneto característico del gongorismo es éste:

Habiendo muerto un toro el caballo a un caballero toreador.

El que Hipogrifo de mejor Rugero, ave de Gaminedes más hermoso, pegaso de Perseo más airoso, de más dulce Arión delfín ligero

fué, ya sin vida yace al golpe fiero de transformado Jove que celoso los rayos disimula belicoso, sólo en un semicírculo de acero.

Rindió el fogoso postrimero aliento el veloz bruto a impulso soberano; pero de su dolor, que tuvo, siento,

más de activo y menos de inhumano, pues fué vergonzoso sentimiento de ser bruto, rigiéndole tal mano. 50

Uno de los más conceptistas por el enredo de palabras y de conceptos es éste:

Yo no puedo tenerte ni dejarte, ni sé por qué al dejarte o al tenerte se encuentra un no sé qué para quererte y muchos sí sé qué para olvidarte.

Pues ni quieres dejarme ni enmendarte, yo templaré mi corazón de suerte que la mitad se incline a aborrecerte aunque la otra mitad se incline a amarte...51

De los elementos gongorinos se puede decir que Sor Juana los ha usado todos: sintaxis latina, metáforas extravagantes, alusiones 
clásicas recónditas, etc. Se siente siempre, sin embargo, que el gongorismo de Sor Juana es algo que usa cuando quiere y como quiere; que comprende sus defectos; mas sus dificultades técnicas la tientan a probar su propia maestría. Que Sor Juana haya admirado e imitado a Góngora no debe extrañar, pues, como hace notar Amado Nervo:

Cuando uno se deja influir por alguien - y no hay poeta en el mundo que no traiga en su plumaje plumas ajenas- debe procurar, por lo menos, que el influyente sea grande, tan grande cual éste, que contagió a colosos como Lope.

Sor Juana, en su espiritual codicia de alteza, hasta en imitar (en lo poquísimo que imitó) fué encumbrada, pues que buscó la semejanza con el máximo ingenio lírico de España, que in illo tempore era tanto como decir del mundo. 52

Este gongorismo que Sor Juana empleó cuando quiso y porque quiso está muy lejos de haber contaminado toda su obra. De las doscientas y tantas poesías que escribió, sólo unas cincuenta son netamente gongorinas. De todas ellas se puede decir lo que el señor Abreu Gómez dice al hablar del Sueño:

... me parece un poema gongorista, superficiamente gongorista, de un poeta conceptuoso. $\mathbf{5 3}$

Si el gongorismo que imitó Sor Juana puede ser considerado como una influencia, pues indudablemente modificó parte de su cbra, el conceptismo que invade gran parte de ella fué más una cualidad innata de su espíritu que una influencia que consciente o inconscientemente le haya venido de afuera. Si Sor Juana hubiera nacido en otro siglo no hubiera gongorizado; pero es probable que su conceptismo hubiera sido muy semejante a lo que es.

En su Respuesta a Sor Philotea de la Cruz habla Sor Juana de su invencible deseo de saber, de ver la relación de una ciencia a otra, de medir y comparar todo en el universo. Es este mismo instinto natural el que la hace retorcer sus conceptos, expresar pensamientos tan profundos que resultan obscuros, y mostrar una agudeza que hubiera causado las delicias de Gracián.

Pero habiendo vivido cuando vivió y habiendo conocido las obras de los conceptistas españoles - de Quevedo y de Gracián a 
To menos-, es probable que éstas hayan influído considerablemente sobre ella, acentuando las tendencias que naturalmente tenía. Así lo dice el señor Toussaint:

Por lo general extrema la nota de ingenio y sucede a veces que cae del todo en la afectación... Algunos de los sonetos de Sor Juana acentúan tanto la ingeniosidad interior, que incurren en verdadero conceptismo por to complicado de la idea ...54

De las obras de Gracián no hay ninguna cita directa, en la poesía de Sor Juana Inés de la Cruz. Se sabe, sin embargo, que las obras de éste formaban parte de su biblioteca, y la manera del gran conceptista español puede haber influído en algunas de las agudezas de la poetisa y en la concisión de lenguaje que a veces la hace obscura.

No parece que tampoco haya ejemplos de imitación directa de las obras de Quevedo en la poesía de Sor Juana, aunque esto no excluye cierta influencia:

E1 rigor conceptual del lenguaje de Sor Juana se acomodó ... a la imitación de los ejemplos de Quevedo. Esta imitación técnica se muestra no sólo en su sintaxis sino también en la conciencia que tuvo de la sobriedad del idioma. Con ella muestra su criterio y su preferencia estética. 55

Lo sutil, agudo e ingenioso de los pensamientos, es muy común en la obra de Sor Juana. Baste con un ejemplo:

Dices que yo te olvido, Cielo, y mientes en decir que me acuerdo de olvidarte, pues no hay en mi memoria alguna parte en que, aun como olvidado, te presentes ...56

Todas las características del conceptismo aparecen en los sonetos de Sor Juana; pero también aparecen en otras de sus composiciones. Sus poesías amorosas -las que escribe un poco en juego, sobre todo- son quizás las más numerosas; pero también hay poesías conceptistas entre las de circunstancias, sus poesías burlescas y algunas de las religiosas. Después de sus sonetos, las décimas son quizás las más conceptistas.

Si la influencia española, al mezclarse con la de la colonia que era entonces la Nueva España, se hizo sentir en Sor Juana como 
gongorismo y conceptismo, también aparece en sencillez y naturalidad, como un reflejo de la escuela tradicional, en sus villancicos y. redondillas. Si el ambiente en que vivió la llevó a veces a gongorizar, y la tendencia de su mente a escribir poemas conceptuosos, su. verdadera alma de poeta supo expresarse también con toda espontaneidad en sus mejores obras.

\author{
Alicia Sarre, Ph. D. \\ Barat College of the Sacred Heart. \\ Lake Forest, Illinois, U. S. A.
}

\title{
NOTAS
}

1 Arturo Torres-Rioseco, "Sor Juana Inés de la Cruz", Revista Iberoamericana, XII (1947), 14.

2 José María Vigil, "Juicio crítico acerca de Sor Juana Inés de la Cruz", citado por Antonio Elías de Molins, en Poesías escogidas de Sor Juana Inés de la Cruz (Barcelona, s. a.), pp. 10-11.

3 Ibid., p. 11.

4 Manuel Toussaint, "Prólogo" a Poesias escogidas de Sor Juana Inés de la Cruz (México, 1916), p. 11.

5 Francisco Pimentel. Historia critica de la poesía en México, Obras.

6 Ibid., p. 181.

7 Dorothy Schons, "The Influence of Góngora on Mexican Literature during the Seventeenth Century", Hispanic Review, VII (1919), 29. pp. 53-54.

8 Ermilo Abreu Gómez, Semblanza de Sot Juana (México, 1938),

9 Luis de Góngora, Obtas poéticas (New York, 1921), 1., 37.

10 Sor Juana Inés de la Cruz, Paesias, edición, prólogo y notas de Ermilo Abreu Gómez (México, 1940), p. 220.

11 Luis Góngora. Obras poéticas, II, 35. En tocas las poesías incluidas en este estudio se ha conservado la ortografía de la obra citada.

12 Sor Juana Inés de la Cruz, Poesías, p. 221.

13 Luis de Góngora y Argote, "Poesías", Poetas líticos de los siglos XVI y XVII, B. A. E. (Madrid, 1950), XXXII, 432. 
14 Sor Juana Inés de la Cruz, Poesías, p. 263.

15 Luis de Góngora y Argote, "Poesías", Poetas liticos de los siglos XVI y XVII, B. A. E., XXXII, 446.

16 Sor Juana Inés de la Cruz, Poesias, pp. 269-270.

17 Dorothy Schons, loc. cit., p. 29.

18 Ermilo Abreu Gómez, "E1 primero sueño de Sor Juana", Contemporáneos, II (1928), 48.

19 Karl Vossler, "La đécima musa de México" en Sor Juana Inés de la Cruz, Obtas escogidas (México, 1934, 4a ed.), pp. 33-34.

20 Sor Juana Inés de la Cruz, Poesías, p. 223.

21 Ibid., pp. 224-226.

22 Ibid., p. 224.

23 Ibid., p. 228.

24 Ibid., p. 230.

25 Ibid., p. 231.

26 Ibid., p. 228.

27 lbid., p. 230.

28 Ibid., p. 232.

29 Ibid., p. 243.

30 Ermilo Abreu Gómez, "Notas" a Sor Juana Inés de la. Cruz, Poesías, pp. 223-253; 292-294.

31 Sor Juana Inés de la Cruz, Poesías, p. 218.

32 Ibid., p. 219.

33 Sor Juana Inés de la Cruz, Poesías completas, Recopilación y prólogo de Ermilo Abreu Gómez (México, 1948, 2a ed.), p. 421.

34 Ermilo Abreu Gómez, "Notas" a Sor Juana Inés de la Cruz, Poesías, p. 287.

35 Sor Juana Inés de la Cruz, Poesías, p. 287.

36 Ibid., p. 212.

37 Ibid., p. 214.

38 Sor Juana Inés de la Cruz, Poesias completas, p. 16. 
39 Ibid., p. 52.

40 Ibid., p. 342.

41 Ibid, p: 263.

42 Sor Juana Inés de la Cruz, Poesias completas, pp. 220-221.

43 Ibid., p. 318.

44 Ibid., p. 358.

45 Ibid., pp. 253 254.

46 Alfred Coester, Historia literatia de la América Española traducción del inglés de Rómulo Tovar (Madrid, 1929), p. 32.

47 Ermilo Abreu Gómez, "Historia literaria de la América Española", Contemporáneos, IX (1931), 187.

48 Juan Hurtado y Jiménez de la Serna y Angel González Palencia, Historia de la literatura española (Madrid, 1934, $2^{\text {a ed.) }}$, p. 540.

49 lbid., p. 575.

50 Sor Juana Inés de la Cruz, Sonetos y endechas, edición y notas de Xavier Villaurrutia (México, 1941), p. 54.

51 Ibid., p. 12.

52 Amado Nervo, Juana de Asbaje, Obras completas (Madrid, 1920), VIII, 83.

53 Ermilo Abreu Gómez, "El primero sueño de Sor Juana", Contempotáneos, II (1928), 49.

54 Manuel Toussaint, op. cit., p. 11.

55 Ermilo Abreu Gómez, "Prólogo" a Sor Juana Inés de la Cruz, Poesías, p. 80 .

56 Sor Juana Inés de la Cruz, Poesias, p. 258. 